\title{
Evolution Education: Seeing the Forest for the Trees and Focusing Our Efforts on the Teaching of Evolution
}

\author{
Nate K. McVaugh • Jeffrey Birchfield • \\ Margaret M. Lucero • Anthony J. Petrosino
}

Published online: 29 December 2010

(C) Springer Science+Business Media, LLC 2010

\begin{abstract}
Evolution is the underlying framework upon which all biology is based; however, when it comes to learning evolutionary concepts, many students encounter obstacles. There are many reasons as to why these obstacles occur. These reasons deal with evolution being treated as a discrete topic among many within a biology curriculum, misunderstanding the nature of science, and personal difficulties with understanding due to evolution's seemingly abstract nature. In this article, we propose a different way of thinking about and teaching evolution in grades $\mathrm{K}-12$, and it surrounds four core areas essential to the understanding of evolution: variation, selection, inheritance, and deep time. Possibilities for how these areas can affect learning are described and implications for assessment are also discussed.
\end{abstract}

Keywords Evolution education - Evolution teaching approaches · Learning progressions · Understanding evolution · Evolutionary beliefs · Evolution curricular approaches

When Charles Darwin proposed his theory of natural selection in the 1800 s, this profoundly changed the social and scientific landscape of the time. Few in society of the time could accept this paradigm shift, but the Darwinian shift had hallmarks of the scientific process, where competing explanations of the natural world were,

\footnotetext{
N. K. McVaugh · J. Birchfield • M. M. Lucero ( $₫) \cdot$

A. J. Petrosino

Department of Educational Psychology,

Learning, Cognition, and Instruction,

University of Texas at Austin,

1 University Station D5700,

Austin, TX 78712, USA

e-mail: mmlucero@mail.utexas.edu
}

and still, looked at through open-mindedness and a critical lens. A similar conflict occurred in geology over Wegener's theory of continental drift. Once mapping of the ocean floor revealed the mid-oceanic ridges and trenches that Wegener's theory required, the geology community quickly adopted the theory, which now forms the basis for understanding much of geology. Evolution holds a similar place in biology. The integration of genetics with evolution that started in the 1930s (Haldane 1932) provided the "missing link" in biology that mid-oceanic ridges had provided to geology. As a result, evolution is the overarching theory that provides the stable bedrock on which biological research and understanding are based. While new details and discoveries in evolution continue to emerge, evolution is the basis for our understanding of biology. Yet despite this centrality, evolution continues to be poorly understood by students, educators, and the public.

Much of the confusion about teaching evolution revolves around specific evolutionary misconceptions (the trees mentioned in the title), which prevent the accurate understanding and integration of evolutionary knowledge into an integrated whole (the forest). This paper will explore broadly the social issues, teaching methods, nature of science, core areas of evolution (variation, selection, inheritance, and deep time), and assessment as they pertain to the learning of evolution. Examination of these areas will shed light on why the learning of evolution can be difficult, and propose a more effective approach to addressing conceptual challenges in this area of biology.

While studies in the teaching and learning of evolution tend to focus upon whether or not student's beliefs influence their understanding of evolution, they may also focus on a specific area of conceptual development (e.g., natural selection). Our work takes these different ways of looking at evolution education and synthesizes it in a way 
that shows how each of these areas are interconnected, as well as how each plays upon the construction of understanding in the area of evolution education. This work was developed with a pragmatist theoretical frame in mind, meaning that we add to the current literature by providing a look at evolution through a cognitive research lens, and use this understanding to guide the development of a curriculum that will address these issues. Rather than concerning ourselves with attempts to change student religious beliefs, we suggest that education professionals focus on the cognitive and conceptual elements students need to integrate for an accurate understanding of evolution.

Central to science and evolution education is the problem that students, parents, and politicians believe they understand evolution, when in fact the vast majority do not. Overconfident self-assessments are resistant to correction. People lack the expertise to recognize their errors (Ehrlinger et al. 2008; Kruger and Mueller 2002; Kruger and Dunning 1999, 2002) and so cannot address them. Even after extensive coursework in biology, many students believe that they understand evolution when in fact they score poorly in understanding and cling to misconceptions. For example, "students who have a long-held impression that evolution is predictably progressive, with the end goal being humans" (Alters and Nelson 2002, p. 1894), or the idea that "theory" is a synonym for "guess." The evolution teaching literature illustrates a wide variety of misconceptions (Alters and Nelson 2002; Anderson et al. 2002; Bishop and Anderson 1990; Brumby 1984; Ferrari and Chi 1998).

\section{Social Issues}

An ongoing concern of educators is the impact of religious resistance to science education in general, and evolution specifically. While this article is not intended to deal with this specific issue, we would be remiss in failing to mention it at all. Religiously based resistance to established science such as biological evolution and an ancient Earth and universe is quite common in both the U.S. and abroad. Many detailed histories of this movement exist (Eve and Harrold 1991; Numbers 1992, 1998), but there is little likelihood that such beliefs will die out, regardless of any amount of evidence to the contrary (Evans 2000a). As a result, science instructors will have to deal with pressure from parents, students, and politicians to defer to particular religious beliefs within the classroom. Such pressures have repeatedly failed in the courtroom, most recently in Dover, Pennsylvania. These rulings insure that science instructors are on firm legal ground when teaching evolution. So far as classroom advice goes, the instructor should point out that evolution is part of the curriculum, and that students are expected to demonstrate their understanding of it, just as they are expected to master other subjects. The instructor however should also point out that there is a difference between understanding something and believing it. In dealing with this issue in the classroom, the instructor should take advantage of the following observations.

A major public concern is that understanding evolution precludes religious belief (Brem et al. 2003). While this may be true for sects that stress "literal" biblical interpretations, such groups are not representative of believers in general. Studies have repeatedly shown that for the large majority of believers, there is little connection between belief in evolution and an understanding of evolution (Bishop and Anderson 1990; Lawson and Worsnop 1992; Lovely and Kondrick 2008; Nussbaum and Sinatra 2003; Sinatra et al. 2003). Indeed, in nations more secular than the U.S. belief in evolution is more common, but public understanding is no better (Abraham-Silver and Kisiel 2008; Dagher and BouJaoude 1997). Conversely, students are able to understand evolution without believing in it. For example, Marcus Ross is a young earth creationist who was awarded a doctorate in geology from the University of Rhode Island (Ross 2007). He and the faculty agreed that his personal beliefs were irrelevant to the quality of his work (Dean 2007). Finally, it should be noted that religious college students that engage in critical thinking about their religious beliefs actually show greater adherence to their faith than those who do not (Hammond and Hunter 1984).

Regardless of home, community beliefs, or education, many children in the U.S. move through a series of stages in their understanding of biological origins of species. Children aged five to 12 years in a Midwestern university town systematically moved from a mix of creationist and spontaneous generation explanations from ages 5.3 to 7.9, to an exclusive creationist stance at ages 8.1 to 10.2 , and finally at ages 10.3 to 12.9 to either evolutionary or creationist explanations (Evans 2000b). This sequence appears to be a result of two factors - the development of abstract thinking, and attempts to incorporate new information into existing conceptions. Family endorsement of evolutionary or creationist explanations had no impact on acceptance.

\section{Teaching Methods}

The literature on student learning shows that even young students have the ability to reason scientifically if given an appropriate context. For example, first (ages five to six) and second grade (ages six to seven) students were able to use scientific reasoning to answer questions in three different contexts (Lehrer and Schauble, 2005). Having students work their way through problems provides a genuine basis for 
learning to occur and allows them to connect terminology with concepts in a meaningful way.

Students have demonstrated scientific reasoning with the utilization and testing of Lamarckian and Darwinian models of speciation (Firenze 1997; Geraedts and Boersma 2006). Jensen and Finley (1996) compared a typical textbook presentation of evolution with an approach that traced the history of ideas about the origin of species from before Darwin through the introduction of his theory, including historical experiments. The historical method produced significantly better understanding in both lecture and paired problem solving.

These approaches all concentrated on contrasting preconceptions with tested scientific explanations. By pairing both conceptions, the student is able to compare misconceptions with actual scientific evidence and to see how these kinds of activities contribute to our understanding (Chinn and Brewer 1993; Kendeou and van den Broek 2005, 2007; Nussbaum and Sinatra 2003; van den Broek and Kendeou 2008).

Children universally adopt misconceptions about the origin of species regardless of the culture in which they were raised (Evans 2000b). For example, during the early to mid-elementary years, fourth through sixth grade children (ages eight to 11) reliably hold essentialist views about living organisms. Species are viewed as being fixed and immutable natural expressions of an underlying "ideal form" for that particular species. Several of these "naive creationist" beliefs are independent of religious beliefs, and thus may be addressed in the classroom. Educators are greatly helped in this endeavor through the intelligent design lobbying industry, which has steadfastly maintained that its publications are empirically based. Books and other media, such as Icons of Evolution (Wells 2002), Darwin on Trial (Johnson 1993), Darwin's Black Box (Behe 1996), and Ben Stein's Expelled (Sullivan et al. 2008), offer a rich source of misconceptions, and provide an excellent starting point for refutation.

Despite evolutionary theory being the foundation on which modern biology is built, it is poorly integrated into the biology curriculum. As Fail (2008) observes, "The public and their school administrative systems seem to have the view that there is 'biological science' and there is 'evolution.' This perceived separateness thus allows for the teaching of biological fact without consideration of how the facts got there" (p. 56).

In U.S. classrooms, evolution is traditionally segregated from the biology curriculum and introduced late in the year. This forces students either to construct a new understanding of biology as they integrate information, or more often to simply compartmentalize the information into isolated chunks, precluding in-depth understanding. Curricula have been developed that introduce evolution in the primary grades (Fail 2003), along with content that supports evolution such as geology and statistics (Petrosino et al. 2003) will produce a more understandable and effective curriculum.

\section{Nature of Science}

It is within the realm of the nature of science that the misconception of how to treat theories, hypothesis, and laws are oftentimes perpetuated and fostered. Teachers and textbooks often suggest that the "scientific method" is a rigid sequence of steps, followed like a recipe and leading to irrefutable results. Such a conception ignores "historical" sciences such as astronomy, archaeology, geology, and biology in which theories integrate a wide number of observations through an explanatory framework.

Understanding how science operates is essential for being able to evaluate the strengths and limitations of science, along with evaluating different types of scientific knowledge (McComas et al. 1998). Describing scientific understanding as a pre-determined, stepwise process leaves students with a distorted understanding of how science is actually conducted.

One promising area of reform is that of learning progressions. Learning progressions attempt to scaffold science concepts through organized, guided, and repeated exposures to science content and ways of thinking over the course of a student's schooling through several curricular units (Songer et al. 2009). By organizing conceptual knowledge around a domain's core ideas, learning progressions provide the support needed for students to become adept at using questions and exploring data in ways similar to experts. More specifically, they describe "successively more sophisticated ways of thinking" within a content domain "that can follow one another as (students) learn about and investigate a topic over a broad span of time" (National Research Council 2007, p. 219). In addition, learning progressions make use of the current research base on conceptual learning and understanding to inform the development of each factor with a learning progression, from identifying the ideas students should learn to assessing where students fall on the scale as defined by the learning progression (Krajcik et al. 2009).

Instructional practices are directly linked to learning progressions, in that learning progressions value effective practices whose goals are to foster understanding by involving students in a variety of practices, including "gathering data through observation or experiment, representing data, reasoning - with oneself and others-about what data mean, and applying key ideas to new situations" (National Research Council 2007, p. 219). Traditional instruction practices are not compatible with the ideas underlying learning progressions, as these practices do not enable most students to achieve a comprehensive understanding of scientific frameworks and/or practices (National 
Research Council 2007). Rather than memorizing and operating from a fixed set of guidelines, students employ their expertise and experience to move between varying pieces of evidence and make connections that inform their understanding of natural phenomena. With regard to evolution and the nature of science, Catley et al. (2005) describe this in their schema as forms of argument. The "Inheritance" section describes the use of learning progressions in more detail.

A more comprehensive program in teaching teachers strategies for implementing scientific argumentation will help to facilitate this process. Teachers also will have to improve their own understanding of the nature and history of science. We now turn to four content areas that provide a foundation for students to develop an accurate understanding of evolutionary theory and facts.

\section{Core Areas}

\section{Variation}

A major challenge is student understanding of statistics. Authors have pointed to a statistical understanding of variation and probability as essential to an accurate understanding of evolution (Gould 1996). While statistics are often considered "too advanced" for younger students, fourth grade students have shown impressive understanding of statistics and reasoning when working through a series of exercises (Petrosino et al. 2003). Similar results have been obtained with fifth grade students (Lehrer and Schauble 2004). Teaching of variation at levels of schooling can occur with success. According to developmental work by Watson et al. (2007), when students at various grade levels had a good understanding of "lower level" variation concepts, they had a fairly high chance for progressing to more conceptually demanding levels. The students may not have necessarily mastered the concepts, but they were ready to learn about different aspects of variation, such as identifying trends in data. Improvements in understanding of evolution are observed when students practice with probabilistic reasoning (Alters 2005), and focus on withinspecies variation (Ferrari and Chi 1998).

\section{Selection}

Gould (1996) proposes that the idea of natural selection is relatively simple and is based on three basic claims: (1) All organisms tend to produce more offspring than can survive; (2) there is variation among organisms within a population; and (3) this variation is passed down to future generations through inheritance. Since natural resources are limited, organisms best suited to their environment will leave more (and better adapted) descendents. Despite appearing to be straightforward, the process of natural selection is frequently misunderstood by high school students (Demastes et al. 1995), undergraduates (Bishop and Anderson 1990), biology majors (Dagher and BouJaoude 1997), medical students (Brumby 1984), and science teachers (Nehm and Schonfeld 2007). Many of these misconceptions are Lamarckian in nature, suggesting that organisms determine what features they need and pass them down to their offspring. According to Ferrari and Chi (1998), this conception of an "intentional, event-like process" is innate to humans, who have a tendency to "perceive all processes as events" that are goal-oriented (p. 1248).

More is involved in inducing conceptual change in evolution than simply memorizing facts, and attempts at conceptual change cannot wait until students are in high school or college. For example, in order to combat naïve essentialism, metamorphosis can be taught at the elementary level (Evans 2008). At the secondary level, having students understand genetic concepts should be achieved first (Banet and Ayuso 2003). Student motivations in the classroom context also influence how easily and thoroughly a student learns about natural selection (Ferrari and Chi 1998). Thematic teaching of evolution is a step in the right direction. In a study of college biology majors, Nehm and Reilly (2007) found that students who were taught with an active-learning strategy with evolution as a common thread through all the units exhibited significant decreases in misconception as opposed to students who were taught with a more traditional lecturing style with one discrete unit on evolution. Instead of valuing test performance, promoting a classroom culture that encourages a mastery orientation to learning scientific concepts aids in inducing conceptual change in students' views.

\section{Inheritance}

In looking at how traits are passed from one generation to the next, we find that most students fail to apply this knowledge to evolution, instead holding that individual "needs" lead to changes throughout the species (Bishop and Anderson 1990; Demastes et al. 1995). These misconceptions are seen both in non-science students and students with a background in biology (Brumby 1984). It is imperative that students are introduced to the concept of inheritance as a vehicle through which species change can occur and the evolutionary process can move onward. High school should not be the first time this concept is introduced; it can very easily be introduced at the elementary and secondary level.

Learning progressions, such as those mentioned in the "Nature of Science" section, have been developed to encourage the understanding of evolution. As described earlier, learning progressions are descriptions of students' 
increasingly complex ideas about a specific field of knowledge over time (Merritt et al. 2008). Developing a learning progression involves centering instruction and assessment around a small number of major foundational concepts of a particular principle (e.g., diversity, variation, change, geologic processes in evolution) and these concepts serve as a collective "pathway" for learning throughout schooling (Catley et al. 2005). Catley et al.'s (2005) primary focus was on how elementary and middle grade students could develop the skills needed to deal with evolution and its use as an overarching theme in the biological sciences. Student knowledge was significantly improved through a number of inquiry activities that strengthened their foundational understanding of evolution. The use of learning progressions can also help form a conceptual framework of an idea or set of ideas. A conceptual framework can be described as how topics and issues within a content area form meaningful relationships. It has been suggested that students are capable of building conceptual frameworks to deal with the understanding of speciation and inheritance even if they have had little introduction to the subject. As previously mentioned, however, elementary students' conceptual frameworks often take on more of an essentialist or creationist tone. As they try to deal with how and why species change over time, students expand previously developed mental constructs that can accommodate evolutionary change (Samarapungavan and Wiers 1997). This integrated understanding avoids the problems associated with developing alternative, compartmentalized constructs that cannot be integrated. The scaffolding needed to deal with inheritance must be provided during the early years of science education, and this can be accomplished through the use of learning progression as explained by Catley et al. (2005).

Doing so will require science teacher education programs to become more adept at introducing this type of concept development in their programs. It is also necessary that we reach teachers who are already in the classroom and introduce them to the construct of using learning progressions for concept development. Using learning progressions will lead to a better understanding of inheritance and also helps the development of schema with which to analyze natural phenomena as a whole. This emphasizes how science is used to evaluate claims and develop an understanding of the natural world, a skill desperately needed as our students come of age in the twenty-first century.

\section{Deep Time}

The concept of deep time plays a substantial role in evolutionary theory, geology, and astronomy. Within a deep time framework it is understood that the universe has existed for a vast amount of millennia and Earth's age is approximately 4.5 billion years old (Dodick and Orion 2003b).
However, in high school biology classrooms, the concept of deep time is rarely mentioned within a discussion of evolutionary theory, even though an understanding of longterm geologic processes is fundamental to mastering the evolutionary concepts. Deep time is poorly understood by the general public, and it has become increasingly evident that pre-service teachers also fail to fully grasp certain geologic events, such as mass extinctions and the appearance of different life forms, because of an insecure deep time cognitive framework (Trend 2000). According to Trend (2001), teachers' confidence with such concepts may be increased through their pre-service and in-service engagement with a variety of teaching and learning strategies, especially those that have constructivist tendencies.

Student understanding of deep time is particularly problematic because little research has paid attention to the cognitive basis for such understanding. Dodick and Orion (2003a, b) developed the Geological Time Aptitude Test (GeoTAT) in order to identify the cognitive factors needed to understand and reconstruct geological systems and structures, such as fossil sequences. They identified three critical factors: (1) the transformation scheme, which describes the degree of change that occurs among a group of objects; (2) knowledge of geological processes, such as fossil formation; and (3) extracognitive factors, such as the understanding of spatial relationships (Dodick and Orion 2003a). In addition, Dodick and Orion suggested that some of the geological principles used in reconstructive thinking could be introduced as early as the seventh and eighth grades. While validating the GeoTAT (Dodick and Orion 2003a), they found that exposure to fieldwork enhanced high school student understanding of temporal organization, and it provided learning about the types of evidence that are necessary in understanding transformational sequences. Building on this work, Catley and Novick (2009) have suggested that deep time is poorly understood by high school and college students due in part to an overemphasis on microevolution, and that deep time should be taught with a relative approach using tree-thinking. Situating deep time within an evolutionary perspective, such as a tree-thinking framework, might go a long way in students' understanding of deep time. According to Catley and Novick, instead of presenting evolutionary "events in disembodied time" (p. 330), secondary teachers should present these events in a relative manner thereby giving students a "holistic trajectory" (p. 330) of such events.

\section{Assessment}

In assessing student knowledge of evolutionary concepts, it is to instructors' advantage if they are made aware of the variety of instruments that have been designed to measure 
such knowledge. Little agreement however exists on what precisely should be measured by these instruments. Many instruments have been concerned with beliefs about evolution as opposed to knowledge of evolution (Brem et al. 2003), or have used qualitative methods that are too time consuming for regular classroom use (Demastes et al. 1995; Demastes et al. 1996; Ferrari and Chi 1998; Samarapungavan and Wiers 1997; Settlage 1994). Instructors interested in quantitative instruments should consult those created by Anderson et al. (2002), Bishop and Anderson (1990), and Settlage and Jensen (1996), all of which assess distinct evolutionary concepts and can be used efficiently with large classes. Instructors may also wish to consider instruments that measure understanding of geological processes (Dodick and Orion 2003b), or the nature of science (Chen 2006). Regardless of instrument used, it is essential that instruments be validated against each other so that their usefulness may be assessed. It is suggested that a suitable governing body such as the American Association for the Advancement of Science work to validate and refine these instruments for national use.

\section{Conclusions}

In this paper, we have tried to shed light on why the learning of biological evolution is so difficult. We have outlined a series of concept topics that are to be introduced and discussed in all biology classrooms so that students and teachers may develop a better understanding. We also propose that this introduction into evolutionary biology should not begin at the secondary level, but at the elementary and middle. While the perception is that older students may be better equipped cognitively to understand some topics, in actuality, properly constructed activities, such as the learning of statistical variability in the fifth grade, can provide a framework for developing a deeper understanding of the construction of science. This scaffolding, once built, can then be used by students to negotiate the complex waters of learning evolution and its place in all facets of the biological sciences.

As educators, education researchers, and policy makers, we should not get tied up in the rhetoric of intelligent design vs. evolution or the semantics of what constitutes a strength and a weakness. We should concern ourselves more with why the topics are difficult to comprehend and teach and how we might use this knowledge in curriculum development, public outreach, and assessment strategies. Let us not miss seeing the beauty of the forest due to the distraction of the trees.

\section{References}

Abraham-Silver L, Kisiel J. Comparing visitors' conceptions of evolution: examining understanding outside the United States. Visit Stud. 2008;11(1):41-54.
Alters B. Teaching biological evolution in higher education: methodological, religious, and nonreligious issues. Sudbury: Jones and Bartlett; 2005.

Alters BJ, Nelson CE. Perspective: teaching evolution in higher education. Evolution: International Journal of Organic Evolution. 2002;56(10):1891-901.

Anderson D, Fisher KM, Norman GJ. Development and evaluation of the conceptual inventory of natural selection. J Res Sci Teach. 2002;39(10):952-78.

Banet E, Ayuso GE. Teaching of biological inheritance and evolution of living beings in secondary school. Int $\mathrm{J}$ Sci Educ. 2003;25:373-407.

Behe MJ. Darwin's black box: the biochemical challenge to evolution. New York: Free Press; 1996.

Bishop BA, Anderson CW. Student conceptions of natural selection and its role in evolution. J Res Sci Teach. 1990;27(5):415-27.

Brem SK, Ranney M, Schindel J. Perceived consequences of evolution: college students perceive negative personal and social impact in evolutionary theory. Sci Educ. 2003;87(2):181-206.

Brumby MA. Misconceptions about the concept of natural selection by medical biology students. Sci Educ. 1984;68(4):493-50.

Catley KM, Novick LR. Digging deep: exploring college students' knowledge of macroevolutionary time. J Res Sci Teach. 2009;46 (3):311-32.

Catley K, Lehrer R, Reiser B (2005) Tracing a prospective learning progression for developing understanding of evolution. In: National Academies Committee on Test Design for K-12 Science Achievement, 2005. National Academy of Sciences, Washington. pp. 2-67.

Chen S. Development of an instrument to assess views on nature of science and attitudes toward teaching science. Sci Educ. 2006;90 (5):803-19.

Chinn CA, Brewer WF. The role of anomalous data in knowledge acquisition: a theoretical framework and implications for science instruction. Rev Educ Res. 1993;63(1):1-49.

Dagher ZR, BouJaoude S. Scientific views and religious beliefs of college students: the case of biological evolution. J Res Sci Teach. 1997;34(5):429-45.

Dean C (2007). Believing scripture but playing by science's rules. New York Times. Retrieved from http://www.nytimes.com/2007/02/12/ science $/ 12$ geologist.html? ei=5094\&en $=$ aabaccdd 1 cf 242 ba $\& h p=\&$ ex $=1171256400 \&$ partner=homepage \&pagewanted $=$ print. Accessed 12 Feb 2007

Demastes SS, Good RG, Peebles P. Students' conceptual ecologies and the process of conceptual change in evolution. Sci Educ. 1995;79(6):637-66.

Demastes SS, Good RG, Peebles P. Patterns of conceptual change in evolution. J Res Sci Teach. 1996;33(4):407-31.

Dodick J, Orion N. Cognitive factors affecting student understanding of geologic time. J Res Sci Teach. 2003a;40(4):415-42.

Dodick J, Orion N. Measuring student understanding of geological time. Sci Educ. 2003b;87(5):708-31.

Ehrlinger J, Johnson K, Banner M, Dunning D. Why the unskilled are unaware: further explorations of (absent) self-insight among the incompetent. Organ Behav Hum Decis Process. 2008;105(1):98121.

Evans EM. Beyond Scopes: why creationism is here to stay. In: Rosengren KS, Johnson CN, Harris P, editors. Imagining the impossible: magical scientific and religious thinking in children. New York: Cambridge University Press; 2000a. p. 305-33.

Evans EM. The emergence of beliefs about the origin of species in school-age children. Merrill Palmer Q. 2000b;46(2):221-54.

Evans ME. Conceptual change and evolutionary biology: a developmental analysis. In: Vosniadou S, editor. International handbook of research on conceptual change. New York: Routledge; 2008. p. 263-94. 
Eve RA, Harrold FB. The creationist movement in modern America. Boston: Twane Publishers; 1991.

Fail J. A no-holds-barred ecology curriculum for elementary and junior high school students. Am Biol Teach. 2003;65(5):341-6.

Fail J. A no-holds-barred evolution curriculum for elementary and junior high school students. Evolution: Education and Outreach. 2008;1:56-64.

Ferrari M, Chi M. The nature of naive explanations of natural selection. Int J Sci Educ. 1998;20(10):1231-56.

Firenze R. Lamarck vs Darwin: dueling theories. Rep Natl Cent Sci Educ. 1997;17(4):9-11.

Geraedts C, Boersma K. Reinventing natural selection. Int J Sci Educ. 2006;28(8):843-70.

Gould SJ. Full house: the spread of excellence from Plato to Darwin. 1st ed. New York: Harmony Books; 1996.

Haldane JBS. The causes of evolution. 1st ed. New York: Harper \& Brothers; 1932.

Hammond PE, Hunter JD. On maintaining plausibility: the worldview of evangelical college students. J Sci Study Relig. 1984;23(3):221-38.

Jensen MS, Finley FN. Changes in students' understanding of evolution resulting from different curricular and instructional strategies. J Res Sci Teach. 1996;33(8):879-900.

Johnson PE. Darwin on trial. Downer's Grove: InterVarsity Press; 1993.

Kendeou P, van den Broek P. The effects of readers' misconceptions on comprehension of scientific text. J Educ Psychol. 2005;97(2):235-45.

Kendeou P, van den Broek P. The effects of prior knowledge and text structure on comprehension processes during reading of scientific texts. Mem Cogn. 2007;35(7):1567-77.

Krajcik JS, Shin N, Stevens SY, Short H. Using learning progressions to inform the design of coherent science curriculum materials. Paper presented at the annual meeting of the American Educational Research Association, San Diego, 2009, April.

Kruger J, Dunning D. Unskilled and unaware of it: how difficulties in recognizing one's own incompetence lead to inflated selfassessments. J Pers Soc Psychol. 1999;77(6):1121-34.

Kruger J, Dunning D. Unskilled and unaware-but why? A reply to Krueger and Mueller. J Pers Soc Psychol. 2002;82(2):189-92.

Kruger J, Mueller RA. Unskilled, unaware, or both? The better-than average heuristic and statistical regression predict errors in estimates of own performance. J Pers Soc Psychol. 2002;82(2):180-8.

Lawson AE, Worsnop WA. Learning about evolution and rejecting a belief in special creation: effects of reflective reasoning skill, prior knowledge, prior belief and religious commitment. J Res Sci Teach. 1992;29(2):143-66.

Lehrer R, Schauble L. Modeling natural variation through distribution. Am Educ Res J. 2004;41(3):635-79.

Lehrer R, Schauble L. Developing modeling and argument in elementary grades. In: Romberg TA, Carpenter TP, Dremock F, editors. Understanding mathematics and science matters. Mahwah, NJ: Lawrence Erlbaum Associates; 2005. p. 29-53.

Lovely EC, Kondrick LC. Teaching evolution: challenging religious preconceptions. Integr Comp Biol. 2008;48(2):164-74.

McComas WF, Almazroa H, Clough MP. The nature of science in science education: an introduction. Sci Educ. 1998;7:511-32.

Merritt JD, Krajcik J, Schwartz Y. Development of a learning progression for the particle model of matter. 2008. Retrieved from http://www.fi.uu.nl/en/icls2008/438/paper438.pdf. Accessed 10 March 2008

National Research Council (NRC). Taking science to school: learning and teaching science in grades K-8. Washington: National Academies Press; 2007.

Nehm RH, Reilly L. Biology majors' knowledge and misconceptions of natural selection. Bioscience. 2007;57(3):263-72.

Nehm RH, Schonfeld IS. Does increasing biology teacher knowledge of evolution and the nature of science lead to greater preference for the teaching of evolution in schools? J Sci Teach Educ. 2007;18(5):699-723.

Numbers RL. The creationists: the evolution of scientific creationism. Berkeley: University of California Press; 1992.

Numbers RL. Darwinism comes to America. Cambridge: Harvard University Press; 1998.

Nussbaum E, Sinatra GM. Argument and conceptual engagement. Contemp Educ Psychol. 2003;28(3):384-95.

Petrosino AJ, Lehrer R, Schauble L. Structuring error and experimental variation as distribution in the fourth grade. Math Think Learn. 2003;5(2\&3):131-56.

Ross MR. Richness trends of mosasaurs (diapsida, squamata) during the late cretaceous. Kingston: University of Rhode Island; 2007.

Samarapungavan A, Wiers R. Children's thoughts on the origin of species: a study of explanatory coherence. Cogn Sci. 1997;21 (2): 147-77.

Settlage JJ. Conceptions of natural selection: a snapshot of the sensemaking process. J Res Sci Teach. 1994;31(5):449-57.

Settlage JJ, Jensen MS. Investigating the inconsistencies in college student responses to natural selection test questions. 1996. Retrieved from http://ejse.southwestern.edu. Accessed 25 August 2008.

Sinatra GM, Southerland SA, McConaughy F. Intentions and beliefs in students' understanding and acceptance of biological evolution. J Res Sci Teach. 2003;40(5):510-28.

Songer NB, Kelcey B, Gotwals AW. How and when does complex reasoning occur? Empirically driven development of a learning progression focused on complex reasoning about biodiversity. Paper presented at the annual meeting of the American Education Research Association, San Diego. 2009, April.

Sullivan J (Producer), Stein B, Miller K (Writers), Frankowski N (Director). Expelled: No Intelligence Allowed. [Motion picture]. United States: Premise Media Corporation. 2008.

Trend RD. Conceptions of geological time among primary teacher trainees with reference to their engagement with geoscience, history and science. Int J Sci Educ. 2000;22(5):539-55.

Trend RD. Deep time framework: a preliminary study of U.K. primary teachers' conceptions of geological time and perceptions of geoscience. J Res Sci Teach. 2001;38(2):191-221.

van den Broek P, Kendeou P. Cognitive processes in comprehension of science texts: the role of co-activation in confronting misconceptions. Appl Cogn Psychol. 2008;22(3):335-51.

Watson JM, Callingham RA, Kelly BA. Students' appreciation of expectation and variation as a foundation for statistical understanding. Math Think Learn. 2007;9(2):83-130.

Wells J. Icons of evolution: science or myth? Why much of what we teach about evolution is wrong. Washington: Regnery Publishing; 2002. 